\title{
Headache and Neuroimaging: Why We Continue to Do It
}

\author{
(D)J.E. Jordan and (1) A.E. Flanders
}

\begin{abstract}
SUMMARY: The appropriate imaging of patients with headache presents a number of important and vexing challenges for clinicians. Despite a number of guidelines and studies demonstrating a lack of cost-effectiveness, clinicians continue to image patients with chronic nonfocal headaches, and the trend toward imaging is increasing. The reasons are complex and include the fear of missing a clinically significant lesion and litigation, habitual and standard of care practices, lack of tort reform, regulatory penalties and potential impact on one's professional reputation, patient pressures, and financial motivation. Regulatory and legislative reforms are needed to encourage best practices without fear of professional sanctions when following the guidelines. The value of negative findings on imaging tests requires better understanding because they appear to provide some measure of societal value. Clinical decision support tools and machine intelligence may offer additional guidance and improve quality and cost-efficient management of this challenging patient population.
\end{abstract}

ABBREVIATIONS: $\mathrm{AI}=$ artificial intelligence; $\mathrm{CDS}=$ clinical decision support; $\mathrm{ED}=$ emergency department

\section{EPIDEMIOLOGY}

A ppropriate imaging for patients presenting with headache continues to be a ubiquitous challenge for clinicians, and headache is an ancient problem-as old as humanity-with ancient references to headache in a number of archaic works. ${ }^{1,2}$ The Ebers Papyrus (1200-1500 BC) referred to headache and other neurologic disorders. Visual symptoms associated with headache were described by Hippocrates in 400 BC. Aretaeus provided one of the earliest classifications of headache around $200 \mathrm{AD}$. Regarding treatment of headache, there is evidence of trepanation of 9000-year-old Neolithic skulls, suggesting some of the first therapeutic approaches. Hippocrates described cupping methods, using a cup to create a partial vacuum to induce blood-flow to the painful site for intense headache pain but cautioned against treatment of more benign headache causes. Aretaeus recommended

Received December 14, 2019; accepted after revision April 9, 2020.

From the Department of Radiology (J.E.J.), Providence Little Company of Mary Medical Center, Torrance, California; Department of Radiology (J.E.J.), Division of Neuroimaging and Neurointervention, Stanford University School of Medicine, Stanford, California; and Department of Radiology (A.E.F.), Division of Neuroradiology/ENT, Jefferson University Hospitals, Philadelphia, Pennsylvania. Paper previously presented, in part, at: Annual Meeting of the American Society of Neuroradiology, May 18-23, 2019; Boston, Massachusetts.

Please address correspondence to John E. Jordan, MD, P.O. Box 6481, San Pedro, CA 90734; e-mail: john.jordan2@providence.org; @johnJordanMD

- Indicates open access to non-subscribers at www.ajnr.org

http://dx.doi.org/10.3174/ajnr.A6591 cupping if bloodletting from the arm or forehead did not relieve headache symptoms. ${ }^{2}$

Much criticism has been generated regarding overuse of advanced imaging modalities, given that most patients with chronic headache and a lack of focal neurologic signs or symptoms will have negative findings. This has been viewed as a costly and wasteful use of resources. Furthermore, headache syndromes account for an estimated 12 million visits per year in the United States, approximating over $\$ 78$ billion per year in direct and indirect costs. ${ }^{1,3,4}$ Direct costs include outpatient services, medications, office or clinic visits, emergency department visits, laboratory and diagnostic services, and management of treatment of adverse effects. Indirect costs include the impact on education, career, earnings, social acceptance, patients' psychological and emotional control over their headaches/ lives, lost days from productive work, housework, and social activities. The life-long prevalence of experiencing any type of headache is $96 \%$. The global prevalence of tension headache is $40 \%$, and migraine, $10 \%{ }^{2,4}$ Of 301 acute and chronic diseases tracked by the Global Burden of Disease studies, 2 headache forms are ranked among those with the highest prevalence, tension and migraine headaches. $^{5-7}$

Headache disorders now rank third among the worldwide causes of disability, measured in years of life lost to disability. ${ }^{6}$ The age-adjusted prevalence of headache $(16.1 \%)$ in US adults ranked third behind low back pain $(28.1 \%)$ and knee pain $(19.5 \%)$ in a review of chronic pain by the Institute of Medicine. ${ }^{8}$ The prevalence rate for headache for the lowest socioeconomic 
groups in the United States is about 75\% higher than in the highest socioeconomic groups. The higher prevalence rates hold true for other causes of chronic pain as well, including low back pain, knee pain, and neck pain. ${ }^{8}$ In short, a greater burden of chronic pain attributable to headache (and other chronic pain syndromes) appears to be borne by those who may have more limited resources for coping with chronic pain.

\section{CLASSIFICATION SCHEMES}

The first proposals in the modern era for the classification of headache disorders were made in the 1960s by the National Institutes of Health and the Research Group on Migraine and Headache of the World Federation of Neurology. ${ }^{9-11}$ However, the work emanating from these groups was limited in that the work merely constituted a listing of a relatively few headache disorders without diagnostic criteria, and the clinical utility was limited. ${ }^{11}$

In 1988, the International Headache Society published the first clinically oriented classification system, the International Classification of Headache Disorders. ${ }^{12}$ This gained international acceptance and is recognized by the World Health Organization as the definitive and reference standard for the classification and categorization of headache disorders. The third edition was published last year (Table 1). ${ }^{13}$ Major US organizations providing clinical guidance include the US Headache Consortium, the American Academy of Neurology,

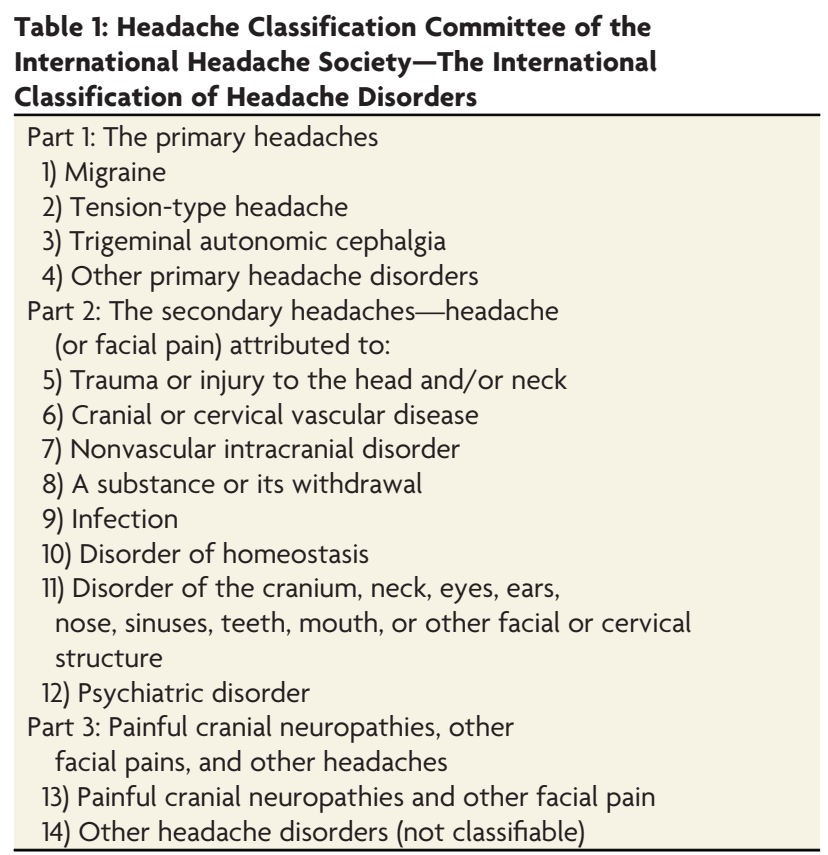

the American College of Emergency Physicians, and the American College of Radiology.

A number of authors have also sought to identify worrisome features that could warrant imaging of patients with headache to provide practical clinical guidance. The pneumonic SNOOP has been used to indicate features that could raise clinical concern and warrant imaging in both adult and pediatric populations such as the presence of the following: systemic symptoms (eg, fever, HIV), neurologic signs, onset pattern (eg, thunderclap, sudden), older age onset, or pattern change. ${ }^{14-17}$ Other red flags include papilledema, systemic illness including rash or neck stiffness, headache triggered by cough or exertion, headache and pregnancy (or postpartum period), worst headache of one's life, and so forth. ${ }^{1}$ The American College of Radiology has endeavored to provide guidance for imaging of patients with headache based on a number of clinical variants. ${ }^{18}$ The American College of Radiology Appropriateness Criteria rank the use of imaging in patients with headache for a given clinical variant with a score of 1-9, with 7-9 meaning usually appropriate, 4-6 may be appropriate, and 1-3 usually not appropriate. If there is wide dispersion of scores among panel members, a ranking of "may be appropriate" can result, corresponding to a score of 5. All scoring is based on expert opinion and the Delphi method, in addition to a critical review of the existing literature. For example, in the case of chronic headache with no new features and normal neurologic examination findings, advanced imaging such as CT or MR imaging would not be considered appropriate. Conversely, a headache with new neurologic features would be considered appropriate for MR imaging or CT, with MR imaging having the highest ranking. A summary of the clinical variants is shown in Table 2.

\section{USE AND COST-EFFECTIVENESS OF IMAGING IN HEADACHE}

Despite the availability of practice guidelines, appropriateness criteria, and practice parameters, the use of imaging in patients presenting with headache appears to be increasing. In a study reviewed in the American Emergency Medical Journal, it was found that imaging of patients presenting to the emergency department during a 10year period (1998-2008) increased from just under 5\% in 1998 to approximately $15 \%$ by $2008,{ }^{19}$ despite the rate of significant intracranial pathology declining in the same period from about $10 \%$ to $<5 \%$. The tripling of the imaging use rate for headache was accompanied by a tripling of the use of CT and MR imaging for all patients presenting to the emergency department. Other research published in JAMA Internal Medicine corroborated the trend with increasing use of neuroimaging for the entire headache population studied from 1995 through 2010, increasing from approximately 5\% in 1995

Table 2: From the American College of Radiology Appropriateness Criteria-Headache Clinical Variants (revised, 2019)

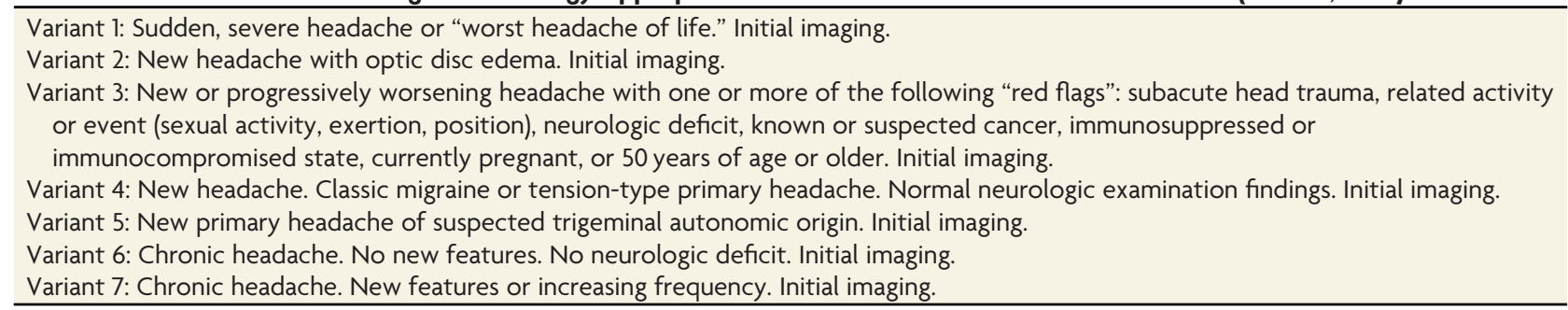


to $15 \%$ in $2010 .^{20}$ Equally concerning is that while advanced imaging use continued to increase, referrals to specialists for the headache population also increased in that time period, as well as the use of certain medications, especially the triptans and ergot alkaloids used to treat migraine headaches. Paradoxically, lifestyle modification that could be an effective tool to reduce use actually decreased from about $23.5 \%$ to $18.5 \%$ in the same period. ${ }^{4}$

The cost-effectiveness of imaging of patients with chronic headache and nonfocal neurologic signs or symptoms is lacking according to a number of published studies. From a historical perspective, even earlier published studies failed to show cost-effectiveness in the imaging of patients with headache and nonfocal neurologic examinations. This finding holds true even though imaging techniques and cost have evolved since the earlier studies. One of the earliest studies was performed by Larson et al, ${ }^{21}$ who found that the cost of finding a case of brain tumor in 1980 was estimated to be at least $\$ 1265$ (\$3805 in 2018 dollars) for patients with abnormal findings on neurologic examinations and $\$ 11,901$ ( $\$ 35,799$ in 2018 dollars) for patients with normal findings on neurologic examinations. Some years later Akpek et $\mathrm{al}^{22}$ found similar results from a sample of 592 patients presenting with headache and no focal findings. Their calculations yielded a cost per clinically significant case using marginal cost estimates of $\$ 23,400$ ( $\$ 41,528$ in 2018 dollars). Jordan et $\mathrm{al}^{23}$ looked at a similarly presenting cohort of 328 patients undergoing MR imaging and hypothesized that MR imaging might be more sensitive in detecting significant pathology than CT. They found that only $1.5 \%$ of patients had clinically significant MR imaging results. The cost per clinically significant managed case detected was $\$ 34,535$ (2018 dollars). No statistically significant difference was found among referring specialties and clinically significant MR imaging results. ${ }^{2}$

Jordan et $\mathrm{al}^{23}$ also studied patients in the emergency department (ED) presenting with headache and nonfocal neurologic examinations, hypothesizing that patients experiencing headache severe enough to prompt an ED visit might result in a higher yield of significant pathology. Their study focused on the use of CT, the most common technique used in EDs across the United States. They found that the cost for the CT and ED visit was approximately 3 times the cost of a routine outpatient visit. Moreover, they found that the incremental cost per clinically significant case detected in the ED was $\$ 50,078$ (2018 dollars). ${ }^{24}$ Even in the pediatric patient population, cost-effectiveness of imaging of patients with headache and nonfocal neurologic examinations is lacking in lower-risk patients. ${ }^{25}$

\section{WHY WE CONTINUE TO IMAGE}

Despite a lack of cost-effectiveness for significant pathology in patients without red flag signs, clinicians continue to fear the consequences of missing significant pathology because it is known that significant pathology can present with a sole symptom of headache. For example, Evans ${ }^{26}$ performed a meta-analysis of the most common secondary causes of headache, reviewing the results of 3026 scans in his analysis. A small percentage of significant abnormalities that are known to manifest with headache was found. He found strokes in $1.2 \%$ of patients in his sample. Brain tumors were found in $0.8 \%$. Other conditions resulting in headache as a sole symptom included hydrocephalus (0.3\%), arteriovenous malformations $(0.2 \%)$, subdural hematomas $(0.2 \%)$, and intracranial aneurysms $(0.1 \%){ }^{26}$ Evans also reviewed the yield of neuroimaging in patients with migraine headaches and no other worrisome features and found a similar low yield of significant pathology known for the potential to manifest with headache. That meta-analysis combined the results of multiple studies during an 18 -year period totaled 1440 scans. The analysis only found an incidence of brain tumor in $0.3 \%$ of patients, arteriovenous malformation in $0.07 \%$, and saccular aneurysm in $0.07 \%$; but it found a higher prevalence of white matter abnormalities reported on MR imaging of $12 \%-46 \% .{ }^{26}$ Notwithstanding the experience in the United States, the National Clinical Guideline Center of the United Kingdom also found in a meta-analysis of 3700 patients with nonfocal headache that only 32 significant abnormalities were found or a yield of $0.86 \%$. The analysis comprised 1800 MR images, 1862 CT scans, and 38 Doppler sonography studies published during approximately 14 years. ${ }^{27}$

A myriad of reasons may be proffered by practitioners, generalists, and specialists when justifying the imaging of patients with headache and a lack of red flags or focal neurologic abnormalities. In addition to the aforementioned, other chief concerns include defensive medicine, community standard of care, professional reputation concerns and fear of sanctions (National Practitioner Data Bank reports, state agency reporting, higher malpractice premiums, and so forth), a desire to avoid patient dissatisfaction, patient-driven demand and insistence on imaging (especially in pediatrics), and self-interest and financial motivation. In the digital age, social media reverberations, patient dissatisfaction, and patient satisfaction surveys heighten the sensitivity of clinicians to patient preferences. Forceful patient demands may be viewed by some practitioners as difficult to resist. These coupled with concerns about litigation and professional sanctions increase the likelihood of capitulation to patient demands, regardless of practice guidelines or imaging yields.

Defensive medicine costs have been considered major drivers of increasing health care expenditures. Furthermore, it appears that physicians are much more likely to blame defensive medicine for a major portion of escalating health care costs than policy makers. A 2005 survey revealed that $93 \%$ of "high-risk" specialists in Pennsylvania reported practicing defensively. ${ }^{28}$ A 2008 study elicited a comparable response from $83 \%$ of Massachusetts physicians. The Massachusetts physicians indicated that between $20 \%$ and $30 \%$ of imaging studies and specialty referrals were ordered primarily for defensive purposes. ${ }^{29}$ An important observation of the study also found that while physicians may initially order additional nonbeneficial tests due to defensive medicine, with time these tests tend to become incorporated into the standard of care of the community. ${ }^{29,30}$

Cost escalation attributable to defensive medicine is difficult to quantify. This issue stems, in part, from the fact that no national claims data exist, making it difficult to quantify these costs on a national scale. Rather, data are available to a varying degree state by state, and the risk profile of a given region may differ significantly from that in others. Nevertheless, policy makers do not fully agree with physicians on the national impact of medical liability costs on US health expenditures. For example, a study designed to estimate this impact found that the overall annual medical liability 
system costs, including defensive medicine, were estimated to be $\$ 55.6$ billion ( $\$ 64.3$ billion, in 2018 dollars) or $2.4 \%$ of total health care spending. ${ }^{31}$ While significant in absolute terms, this is far below the $20 \%-30 \%$ of health expenditures often estimated by physicians and others. ${ }^{30}$ The truth may lie somewhere between the two, but this is an important subject requiring further study.

\section{VALUE AND NEGATIVE IMAGING RESULTS}

The increasing trend toward imaging lower-risk patients with chronic headache is commonly assumed to be of limited value when imaging study findings are negative; these studies are viewed as both costly and wasteful. Yet these assumptions may be too simplistic. "Value" is a term that is not coterminous with cost when it comes to health expenditures, and value from the patient's perspective is not necessarily coterminous with that of payers or policy makers. ${ }^{32}$ Negative test results are often highly valued by patients and providers, and this feature appears to underestimate the true societal value of imaging tests with negative findings when it comes to patients presenting with headache.

Imaging tests with negative findings may result in a reduction of patient or family anxiety, providing an anxiolytic effect for multiple parties (including providers). Other benefits of negative imaging results of patients with headache may include improvement in productivity, reduction in subsequent medical visits to both generalists and specialists, a reduction of subsequent costs of imaging, school performance improvement, decreases in psychological and behavioral problems, as well as opportunities for treatment of incidental findings such as sinus disease, which might actually be the cause of a headache. ${ }^{23,27,33}$

It has been shown that in patients presenting with chronic headache, those offered imaging earlier were less likely to be referred to a specialist such as a neurologist or psychiatrist. ${ }^{33}$ This finding was even more striking when comparing patients with psychological or psychiatric disorders using proxy measures (Hospital Anxiety and Depression Scale), with a greater propensity toward referral among patients with positive results on the Hospital Anxiety and Depression Scale. A trend toward a decrease in subsequent imaging for those offered scanning sooner was also observed but not at the same level of statistical significance. ${ }^{33}$ Referrals to specialists may generate further work-ups and interventions in addition to imaging, resulting in increases in direct costs for patients not offered imaging sooner rather than later. Indirect costs arising from patient anxiety such as reductions in productivity or time lost from work, school, and so forth also appear to take a toll and may be more costly from a societal perspective. Hence, imaging may be anxiolytic and reduce the anxiogenic effects and downstream costs resulting from not providing patients (and providers) with answers regarding their headaches early on.

The value of negative findings on imaging tests should not be overlooked, and this is an important area requiring further study. In the case of headache, further study of the anxiolytic effects of imaging also requires additional investigation. A growing body of literature has begun elucidating the clinical and economic benefits that can accrue from negative findings on imaging tests. Although beyond the scope of this manuscript to review in detail, such studies range from imaging using coronary CTA to lung cancer screening, etc., which is in contrast to the many studies looking at various imaging modalities and organ systems with respect to negative or positive predictive value. ${ }^{34-36}$

\section{POTENTIAL REMEDIES AND FUTURE DIRECTIONS}

Unquestionably, patients presenting with headache even in the chronic low-risk setting will continue to challenge practitioners and bring with them the inexorable pressures to image. Therefore, potential solutions and remedies must be multifaceted. With respect to defensive medicine, federal tort reform has been advocated by some to help shield practitioners from litigation if following practice guidelines. In the era of evidence-based medicine and best practices, such protections are becoming increasingly important, not only for improved patient management and outcomes but also for the most optimal allocation of limited resources. ${ }^{37}$ Examples of tort reform include the capping of damages in medical malpractice cases or limiting professional sanctions if clinicians are following guidelines. Currently $>30$ states have laws limiting damages. $^{38}$ Such approaches may reduce malpractice insurance costs but probably will not eliminate defensive medicine practices without other measures being taken. ${ }^{39}$

State tort reform or federal tort reform or both are often advocated as a way to reduce damages and costs related to medical liability as well as reducing cost associated with the practice of defensive medicine. However, tort reform legislation can be challenged under the Fifth Amendment Equal Protection Clause and the Seventh Amendment clause on the right to a jury trial under the US constitution. ${ }^{40,41}$ Notwithstanding, few federal courts have overturned malpractice tort reform, and it is unlikely that the Supreme Court would overturn federal malpractice tort reform because the lowest level of scrutiny is typically applied in reviewing the constitutionality of tort reform statutes. ${ }^{40,41}$ In other words, if there is a rational public policy reason for the legislation, the courts are unlikely to overturn it.

The adoption of a no-fault system to compensate patients injured during medical practice has also been advocated as a potentially less costly and fairer way to deal with medical injuries. ${ }^{42}$ This contrasts with the US tort liability system, which is considered a type of social insurance to compensate for injuries in a marketbased economy. No-fault systems have become more popular in many developed Organization for Economic Cooperation and Development countries and are considered social insurance of goodwill, wherein the patients are compensated for medical injury without regard to a provider's fault. ${ }^{42}$ Moreover, no-fault systems are thought to be more efficient, fairer, and less costly. Judgment under such systems is more likely to rely on the opinions of experts rather than lay people as currently practiced under the jury system in the United States.

Other potential remedies and future directions include comparative effectiveness studies in the work-up and management of headache (eg, pharmaceuticals versus lifestyle interventions) and followup costs; alternative screening studies and/or alternate imaging approaches; patient cost-sharing of diagnostic testing; regulatory reform (eg, National Practitioner Data Bank, state reporting requirements); and clinical decision support and artificial intelligence (AI) tools. Relatively few studies have reviewed the comparative effectiveness of alternative approaches for the diagnosis and management of headache using nontraditional means, though 
some studies have examined the comparative effectiveness of various pharmacologic therapies. ${ }^{43}$ Yet, alternative approaches may be more cost-effective and improve outcomes for patients with chronic headache, particularly when there is a focus on preventative measures. For example, appropriate lifestyle interventions could be very effective in the management and prevention of headache while obviating more expensive interventions and imaging. ${ }^{44}$ Alternative approaches may also avoid the complications of pharmacotherapies and medication overuse, which, in and of themselves, can have debilitating effects and result in the need for further costly interventions. ${ }^{5,45}$

Alternative imaging algorithms could be considered to ease patient and provider anxiety, given the anxiolytic effects that such information can provide. ${ }^{33}$ For example, a significantly scaleddown version of a brain MR imaging examination might suffice with 1 or 2 sequences, while being less costly than conventional brain MR imaging protocols. ${ }^{15}$ Moreover, patient cost-sharing could select patients who have a strong desire for imaging despite the absence of good clinical indications or red flags. In such cases, the patient's willingness to pay could inform policy prescriptions and decision-making, while reducing the burden on payers. In the current environment, patients are increasingly expressing a willingness to assume some costs for their health care. A recent survey conducted by Deloitte regarding consumer health preferences indicated that younger generations are more likely to be willing to pay some of their health care costs than older generations. ${ }^{46}$ This survey has important implications for policy makers not only in the management of headache but for other disorders as well, given the recognition of limited resources for health expenditures. However, differential consumer payment schemes for health care can increase the risk of multitiered systems and disparities in health care.

In addition to tort reform, regulatory reform regarding physicians' credentials and reporting should also be an important consideration to counter defensive medicine practices. Calls for tort reform, even if successful, are unlikely to diminish defensive medicine practices as long as physicians fear professional sanctions and impugnment of their reputations. Malpractice judgments and regulatory requirements to report such verdicts (or even settlements) to state board agencies and the National Practitioner Data Bank can have chilling effects on physicians' practice patterns and cause them to be risk-averse. Even simple patient reports to licensing authorities can result in exhaustive and intimidating reviews of a physician's practices and credentials. Hence, even limiting damages to small dollar amounts would be unlikely to reassure physicians if their reputations could still be impugned in the process. Both best-practice guidelines that shield physicians following them and no-fault systems of awarding damages for injured patients would, in conjunction with tort reform, be more likely to shift the calculus affecting the behavior of physicians when it comes to defensive medicine.

Finally, clinical decision support (CDS) tools and AI algorithms also appear to be promising for helping clinicians navigate this complex clinical and public health problem. CDS systems are designed to provide clinicians, staff, patients, and others with knowledge and person-specific information, to enhance health and health care. ${ }^{47}$ CDS comprises tools such as computerized alerts, reminders to providers and patients, clinical guidelines, conditionspecific order sets, and focused patient data reports. ${ }^{47}$ Most CDS applications operate as components of electronic health records, though stand-alone CDS systems are also becoming increasingly available. Newer and fastest-growing CDS tools are powered by AI, neural networks, or deep/machine learning techniques. The recent guidance by the FDA on classifying and regulating CDS systems has been considered too ambiguous for developers to effectively follow. These systems have not been included in the FDA medical device category and therefore are not subject to FDA oversight, though effort is underway to change this. ${ }^{48}$

Emerging studies examining the role that AI could play in diagnosing and managing patients with headache have recently begun to appear in the literature. For example, a case-based reasoning AI-powered Clinical Decision Support System study diagnosed primary migraine and primary tension headache with a high degree of accuracy and performed better than the guidelinebased Clinical Decision Support System (International Headache Society-International Classification of Headache Disorders). ${ }^{49}$ It has also been shown that machine learning methods and feature selection can be used to support specialists in the classification of migraines automatically in patients undergoing MR imaging using DTI biomarkers. ${ }^{50}$

A recent study presented at the 70th Annual Meeting of the American Academy of Neurology in Los Angeles examined the safety of an artificial intelligence system for nonacute headache diagnosis and compared an AI system with the performance of neurologists in the diagnosis of nonacute headaches. ${ }^{51}$ The study compared the performance of a support vector machine model in classifying the headache as primary versus secondary with that of 2 general neurologists. The support vector machine model trained to "read" clinical records had a better performance in the diagnosis of secondary headache (sensitivity $=90.2 \%$; specificity $=93 \%$ ) compared with the neurologists (sensitivity $=82 \%$; specificity $=85 \%$ ), and the correct headache diagnosis was achieved in $89 \%-94 \%$ of cases when the International Classification of Headache Disorders criteria were combined with machine learning models. Hence, early work in AI shows the potential to help generalist clinicians evaluate and manage difficult and often confusing cases of headache, on a par with or exceeding the skill of specialists.

\section{CONCLUSIONS}

Despite a number of guidelines and studies demonstrating a lack of cost-effectiveness, clinicians continue to image patients with chronic nonfocal headaches, and the trend toward imaging is increasing. The reasons for this prevailing trend are complex and include the fear of missing a significant lesion and litigation, habitual and standard of care practices, lack of tort reform, regulatory penalties and the potential impact on one's professional reputation, patient pressure, and financial motivation. There is a need for further clarity on the cost of imaging versus not imaging (direct and indirect), especially with respect to the anxiolytic effects on patients. Scaled-down, less costly screening studies may offer alternative approaches. Comparative effectiveness studies, lifestyle interventions, and preventive measures must be further studied to identify the most effective and cost-effective measures that can be undertaken to assuage concerns and the tendency to 
image patients with headache when clinical signs do not warrant it. Regulatory and legislative support to encourage best practices without fear of financial and professional sanctions when following guidelines is needed. Moreover, serious consideration needs to be given to the adoption of no-fault systems for compensation of injured patients currently practiced in many Organization for Economic Cooperation and Development countries.

Radiologists and other clinicians should be well-versed and conversant regarding the value of imaging tests with negative findings because they appear to provide some measure of value, from patient and societal perspectives, but further study is also needed in this area. Patient cost-sharing and willingness-to-pay schemes are worth exploring in the light of limited resources for health expenditures. Clinical decision support tools, AI, and machine learning may offer additional guidance and improve quality and cost-efficient management of this challenging patient population.

\section{REFERENCES}

1. Rizzoli P, Mullally WJ. Headache. Am J Med 2018;131:17-24 CrossRef Medline

2. Koehler PJ, Boes CJ. A history of non-drug treatment in headache, particularly migraine. Brain 2010;133:2489-2500 CrossRef Medline

3. Gooch CL, Pracht E, Borenstein AR. The burden of neurological disease in the United States: a summary report and call to action. Ann Neurol 2017;81:479-84 CrossRef Medline

4. Mafi JN, Edwards ST, Pedersen NP, et al. Trends in the ambulatory management of headache: analysis of NAMCS and NHAMCS Data 1999-2010. J Gen Intern Med 2015;30:548-55 CrossRef Medline

5. Global Burden of Disease Study 2013 Collaborators. Global, regional, and national incidence, prevalence, and years lived with disability for 301 acute and chronic diseases and injuries in 188 countries, 1990-2013: a systematic analysis for the Global Burden of Disease Study 2013. Lancet 2015;386:743-800 CrossRef Medline

6. Steiner TJ, Birbeck GL, Jensen RH, et al. Headache disorders are third cause of disability worldwide. J Headache Pain 2015;16:58 CrossRef Medline

7. Probyn K, Bowers H, Caldwell F, et al; CHESS Team. Prognostic factors for chronic headache. Neurology 2017;89:291-301 CrossRef Medline

8. Institute of Medicine (US) Committee on Advancing Paid Research, Care, Education, and Research. Relieving pain in America: a blueprint for transforming prevention, care, education, and research. National Academies Press; 2011 Medline

9. Ad Hoc Committee on Classification of Headache of the National Institute of Health. Classification of headache. JAMA 1962;179: 717-18

10. World Federation of Neurology Research Group on Migraine and Headache. J Neurol Sci 1969;9:202

11. Olesen J, Steiner TJ. The International Classification of Headache Disorders, 2nd edn (ICDH-II). J Neurol Neurosurg Psychiatry 2004;75:808-11 Medline

12. Classification and diagnostic criteria for headache disorders, cranial neuralgias and facial pain: Headache Classification Committee of the International Headache Society. Cephalalgia 1988;8:(suppl 7): 1-96 Medline

13. Headache Classification Committee of the International Headache Society (HIS): the International Classification of Headache Disorders, 3rd edition. Cephalalgia 2018;38:1-211 CrossRef Medline

14. Dodick DW. Diagnosing headache: clinical cues and clinical rules. Advanced Studies in Medicine 2003;3:87-92

15. Trofimova A, Vey BL, Mullins ME, et al. Imaging of children with nontraumatic headaches. AJR Am J Roentgenol 2018;210:8-17 CrossRef Medline
16. Gofshteyn JS, Stephenson DJ. Diagnosis and management of childhood headache. Curr Probl Pediatr Adolesc Health Care 2016;46:3651 CrossRef Medline

17. Nye BL, Ward TN. Clinic and emergency room evaluation and testing of headache. Headache 2015;55:1301-08 CrossRef Medline

18. Whitehead MT, Cardenas AM, Corey AS, et al; Expert Panel on Neurologic Imaging. American College of Radiology. ACR Appropriateness Criteria: Headache. 2019. https://acsearch.acr.org/docs/ 69482/Narrative/. Accessed July 30, 2019

19. Gilbert JW, Johnson KM, Larkin GL, et al. Atraumatic headache in US emergency departments: recent trends in CT/MRI utilization and factors associated with severe intracranial pathology. Emerg Med J 2012;29:576-81 CrossRef Medline

20. Callaghan BC, Kerber KA, Pace RJ, et al. Trends in neuroimaging utilization for the entire headache population from 1995 through 2000 and 2005 through 2010. JAMA Intern Med 2014;174:819-21 CrossRef Medline

21. Larson EB, Omenn GS, Lewis H. Diagnostic evaluation of headache: impact of computerized tomography and cost-effectiveness. JAMA 1980;243:359-62 CrossRef Medline

22. Akpek S, Arac M, Atilla S, et al. Cost-effectiveness of computed tomography in the evaluation of patients with headache. Headache 1995;35:228-30 CrossRef Medline

23. Jordan JE, Ramirez GF, Bradley WG, et al. Economic and outcomes assessment of magnetic resonance imaging in the evaluation of headache. J Natl Med Assoc 2000;92:573-78 Medline

24. Jordan YJ, Lightfoote JB, Jordan JE. Computed tomography imaging in the management of headache in the emergency department: cost efficacy and policy implications. J Natl Med Assoc 2009;101:331-35 CrossRef Medline

25. Medina LS, Kuntz KM, Pomeroy S. Children with headache suspected of having a brain tumor: a cost-effectiveness analysis of diagnostic strategies. Pediatrics 2001;108:255-63 CrossRef Medline

26. Evans RW. Diagnostic testing for the evaluation of headaches. Neurol Clin 1996;14:1-26 CrossRef Medline

27. Kennis K, Kernick D, O’Flynn N; National Clinical Guideline Centre for Acute and Chronic Conditions, Royal College of Physicians, London. Diagnosis and management of headaches in young people and adults; NICE Guideline. Br J Gen Pract 2013;63:443-45 CrossRef

28. Studdert DM, Mello MM, Sage WM, et al. Defensive medicine among high-risk specialist physicians in a volatile malpractice environment. JAMA 2005;293:2609-17 CrossRef Medline

29. Rothberg MB, Class J, Bishop TF, et al. The cost of defensive medicine on 3 hospital medicine services. JAMA Intern Med 2014;174:1867-68 CrossRef Medline

30. Hermer LD, Brody H. Defensive medicine, cost containment, and reform. J Gen Intern Med 2010;25:470-73 CrossRef Medline

31. Mello MM, Chandra A, Gawande AA, et al. National costs of the medical liability system. Health Aff (Millwood) 2010;29:1569-77 CrossRef Medline

32. Porter ME. What is value in health care? N Engl J Med 2010;363:247781 CrossRef Medline

33. Howard L, Wessely S, Leese M, et al. Are investigations anxiolytic or anxiogenic? A randomised controlled trial of neuroimaging to provide reassurance in chronic daily headache. J Neurol Neurosurg Psychiatry 2005;76:1558-64 CrossRef Medline

34. Faxon DP, McCabe CH, Kreigel DE, et al. Therapeutic and economic value of a normal coronary angiogram. Am J Med 1982;73:500-5 CrossRef Medline

35. Frishberg BM. The utility of neuroimaging in the evaluation of headache in patients with normal neurologic examinations. Neurology 1994;44:1191-97 CrossRef Medline

36. Smulders MW, Jaarsma C, Nelemans PJ, et al. Comparison of the prognostic value of negative non-invasive cardiac investigations in patients with suspected or known coronary artery disease-a metaanalysis. Eur Heart J Cardiovasc Imaging 2017;18:980-87 CrossRef Medline 
37. Hoesing $\mathrm{H}$; Joint Commission International. Clinical Practice Guidelines: Closing the Gap Between Theory and Practice. Elsevier 2016. https://www.elsevier.com/clinical-solutions/insights/resources/ insights-articles/clinical-practice/clinical-practice-guidelines-closingthe-gap-between-theory-and-practice. Accessed August 24, 2019

38. Ryskamp D. Medical Malpractice Damages Caps: A State by State Comparison. Expert Institute. February 14, 2019. https:// www.theexpertinstitute.com/medical-malpractice-damages-caps-astate-by-state-comparison/. Accessed October 18, 2019

39. Waxman DA, Greenberg MD, Ridgely MS, et al. The effect of malpractice reform on emergency department care. $N$ Engl J Med 2014;371:1518-25 CrossRef Medline

40. Office of Technology Assessment (OTA). "Impact of legal reforms on medical malpractice costs." Library Office of Technology Assessment, US Congress, Washington DC. 20510. https://www.princeton. edu/ ota/disk1/1993/9329/9329.PDF. Accessed August 25, 2019

41. Turkington RC. Constitutional limitations on tort reform: have the state courts placed insurmountable obstacles in the path of legislative responses to the perceived liability insurance crisis? Villanova Law Review 1987;32:1299

42. Medical Malpractice Systems around the Globe: Examples from the US- tort liability system and the Sweden- no fault system. Document of the World Bank. http://documents.worldbank.org/ curated/en/421621468779085220/pdf/290110English0malpractice1 systems.pdf. Accessed August 25, 2019

43. Jackson JL, Cogbill E, Santana-Davila R, et al. A comparative effectiveness meta-analysis of drugs for the prophylaxis of migraine headache. PLoS One 2015;10:e0130733 CrossRef Medline
44. Sheeler RD, Garza I, Vargas BB, et al. Chronic daily headache: ten steps for primary care providers to regain control. Headache 2016;56:167584 CrossRef Medline

45. Westergaard ML, Munksgaard SB, Bendtsen L, et al. Medication-overuse headache: a perspective review. Ther Adv Drug Saf 2016;7:147-58 CrossRef Medline

46. What matters most to the health care consumer? Insights for health care providers from the Deloitte 2016 Consumer Priorities in Health Care Survey. https://www2.deloitte.com/us/en/pages/lifesciences-and-health-care/articles/us-lshc-consumer-priorities-promo. html. Accessed September 26, 2019

47. Clinical Decision Support. Office of the National Coordinator for Health Information Technology (ONC). https://www.healthit.gov/topic/ safety/clinical-decision-support. Accessed August 25, 2019

48. Wicklund E. FDA Urged to Clarify Clinical Decision Support Regulations. mHEALTH INTELLIGENCE. https://mhealthintelligence.com/ news/fda-urged-to-clarify-decision-support-regulations. Accessed August 19, 2019

49. Yin Z, Dong Z, Lu X, et al. A clinical decision support system for the diagnosis of probable migraine and probable tension-type headache based on case-based reasoning. J Headache Pain 2015;16:29 CrossRef Medline

50. Garcia-Chimeno Y, Garcia-Zapirain B, Gomez-Beldarrain M, et al. Automatic migraine classification via feature selection committee and machine learning techniques over imaging and questionnaire data. BMC Med Inform Decis Mak 2017;17:38 CrossRef Medline

51. Acosta J, Grimaldi F, Dorr F, et al. Accuracy and safety of an artificial intelligent system for nonacute headache diagnosis. Neurology 2018;90:(Suppl 15) 